\title{
Effect of Traditional Fermentation Time on Total Phenolic Content and In vitro Antioxidant Activity of Kocho: Ethiopian Fermented Food from Enset (Ensete ventricusum welw. Chessman)
}

\author{
Engeda Dessalegn \\ Department of Chemistry, Hawassa College of Education, P.O. Box 115, Hawassa, Ethiopia
}

\begin{abstract}
Ensete ventricusum, locally known as Enset, is the main crop of a sustainable food source that ensures food security in Central ,South and South West Ethiopia. It has been used as a food and local medicine for thousands of years. Kocho is a product of matured Enset prepared traditionally by fermenting (for few weeks to some months) a mixture of pulverized pseudostem and corm in pit. The objective of this study was to evaluate the effect of traditional fermentation period on the total phenolic content and antioxidant activity of Kocho. The sample was fermented in the pit for 15, 30, 45, 60, 75, 90, 105 and 120 days. Oven dried Kocho powder was extracted with methanol followed by water. Total phenolic content of the extract was determined by the Folinciocalteu method. Antioxidant activities of the extracts were evaluated with 2, 2-diphenyl-1-picrylhydrazyl (DPPH) scavenging activity and total antioxidant activity using phosphomolybdenum assay. The results revealed that Kocho showed greater total phenolic content and antioxidant activities than unfermented product. Methanol extract of Kocho fermented for 45 days showed the highest amount of total phenolic content $(9.27 \pm 0.44$ milligram of gallic acid equivalent per gram of dried extract). In comparison of DPPH scavenging and total antioxidant, methanol extracts were also superior to aqueous extracts. Methanol extract of Kocho fermented for 60 days exhibited the strongest $\mathrm{DPPH}$ scavenging activity $\left(\mathrm{IC}_{50}=0.15 \pm 0.02 \mathrm{mg} / \mathrm{mL}\right)$ and total antioxidant activity ( $0.43 \pm 0.04$ milligram of ascorbic acid equivalent per gram of dried extract). Thus fermentation offers a tool to further increase the bioactive compounds and antioxidant potential of Kocho.
\end{abstract}

Keywords: antioxidant activity, Ensete ventricusun, , fermentation, Kocho, total phenolic

DOI: $10.7176 / \mathrm{FSQM} / 91-05$

Publication date:October $31^{\text {st }} 2019$

\section{Introduction}

Enset is one of the potential indigenous crops for food, and the Enset cultivation system is economically viable, and is one of the few successful indigenous and sustainable agricultural systems (Yemataw et al., 2018). It is sustainable because it has been providing food for humans for generations from the same plot, and maintains the quality of life of the people (Negash and Anke 2004). It grows in a wide range of environmental conditions. Even though it is grown in many wide areas of the world, the people of the central and southern parts of Ethiopia are the only people that use Enset as a staple and co-staple crop.

Enset (Ensete ventricosum) products are one of the main energy sources of foods for about 20 million people in south and south western Ethiopia (Brandt et al., 1997). It is related to and resembles banana plant produced primarily for the large quantity of carbohydrate-rich food. The major food types obtained from Enset are Kocho, Bulla and Amicho. Kocho is the bulk of the fermented food obtained from the mixture of the decorticated (scraped) leaf sheaths and grated corm (Tiruha et al., 2014) (underground stem base). Bulla is obtained by squeezing out the liquid containing starch from scraped leaf sheathes and grated corm and allowing the resultant starch to concentrate into white powder. Amicho is boiled Enset corm pieces, mainly obtained from young Enset plants that are prepared and consumed in a similar manner to other root and tuber crops (Zerihun et al., 2014). Starch is the major component of fermented Enset comprising approximately $99.24 \%$ of the dry weight and is in the form of granule size of $46 \mu \mathrm{m}$ (Gebre-Mariam \& Schmidt, 1996). The recent study (Zenebe et al., 2018) on fibers, obtained from the scraping of the pseudo stem, as well as the inflorescence stalk remaining after leaves sheath removal, showed the presence of lignin, polysaccharides and extractives.

Besides the macronutrient, study was conducted on micronutrient from ten Enset varieties collected from Sidama zone of southern Ethiopia. Samples of leaf lamina, leaf midrib, pseudostem and corm were taken at the age of 5 to 6 years during the main rainy season. Most Enset fractions were rich sources of major minerals such as phosphorus, potassium, calcium (except corm) and magnesium. Sodium content was very low (Ajebu et al., 2008). According to the study conducted by Foesido et al. (2013), Enset products had higher fiber, calcium, potassium, magnesium and manganese content as compared to wheat and corn.

Besides its use as a source of food, Enset is also utilized for animal forage, fiber production, construction material, as ornament, and for its medicinal values (Samuel M. 2014; Melese et al., 2015). Among the Gurage people, South Ethiopia, different varieties of Enset have played a considerable role in traditional medicine which 
demonstrated antimicrobial activity against viral, bacteria, fungal and nematodal diseases of humans (Holscher D. and Schneider B. 1998). Some of the Enset varieties are used as medicines by local people for both humans and livestock to cure bone fractures, joint displacement, broken bones, and childbirth problems ie, assisting to discharge the placenta (Balcha, 1990). So far, Biruk et al. (2012) studied Enset starch for industrial uses and found a characteristics of high gelatinization property whereas Gebre-Mariam and Schmidt (1996) obtained its use as a binder and disintegrant for tablets.

Though Enset is widely used as food source and traditional medicine, scarce information is available on the antioxidant activities of food products of this plant (Forsido et al., 2013). To my knowledge no study has been reported on the effect of fermentation period on total phenolic contents and antioxidant potential of Kocho. Therefore, the objective of the present study was to evaluate the effect of traditional fermentation period on total phenolic content and in vitro antioxidant activities of aqueous and methanol extracts of Kocho. In addition, the correlation between total phenolic content and antioxidant activities was also evaluated.

\section{Methods and Materials}

\subsection{Chemicals}

Gallic acid, butylated hydroxyl toluene (BHT), Folin-Ciocalteau reagent, 2,2-diphenyl-1-picrylhydrazyl (DPPH), sodium phosphate, ammonium molybdate, and ascorbic acid were purchased from sigma-aldrich. The other chemicals and solvents used in this experiment were of analytical grade.

\subsection{Sample Collection and Preparation}

Enset local variety known as "Adew" was used for this experiment. The Enset plant was 4 years old grown in 5 Km South of Hawassa town, Sidama zone, South Ethiopia. Woman having traditional experience about the preparation of Kocho was selected to carry out the processing following the traditional farmers' practices. The scraped and pulverized masses (Figure 1A) were thoroughly mixed with small amount of previously fermented Kocho (as starter of fermentation) and placed in the pit (Figure 1B), lined with Enset leaves and left for fermentation at ambient temperature. A portion of fermented sample (Kocho) was removed from the pit and the liquid was squeezed out of it, resulting into a moist fibrous Kocho (Figure 1C). Sample was collected every 15 days for analysis, up to four months from the date of processing until final fermentation stage and the samples were tested for the total phenolic content and antioxidant activities.

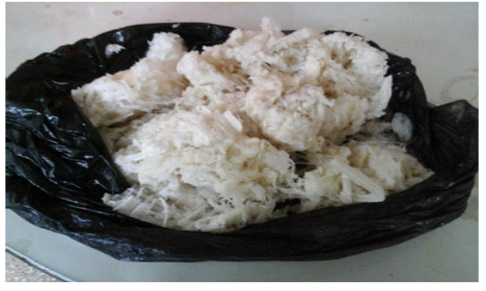

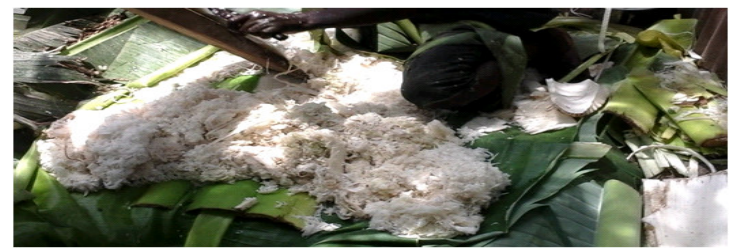

B

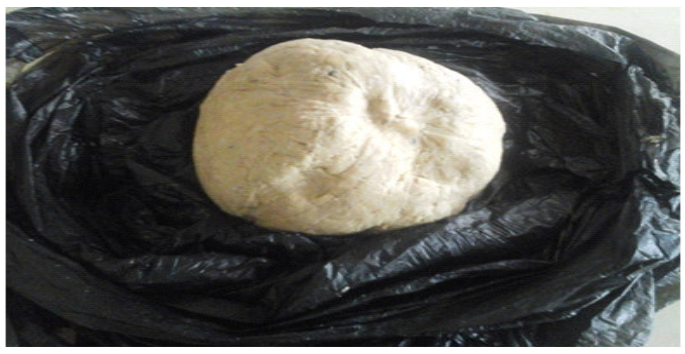

C

Figure 1: Mixture of decorticated leaf sheaths, the grated and pulverized corm and pseudostem (A), mixture of decorticated leaf sheaths and the grated and pulverized corm and pseudostem in the pit (B), fermented Kocho (C).

\subsection{Preparation of Kocho Extracts}

After oven dried (at $50^{\circ} \mathrm{C}$ ) sample was ground to fine powder using electric grinder (FM100 model, China). The aqueous and methanol extracts of all were prepared by dissolving $10 \mathrm{~g}$ of the samples fine powder separately in $100 \mathrm{~mL}$ of each solvent. The contents were kept in orbital shaker for $6 \mathrm{~h}$ at room temperature. Thereafter, each extract was filtered using Whatman no. 1 filter paper and evaporated to dryness under vacuum at $40^{\circ} \mathrm{C}$ by using a rotary evaporator (Buchi, 3000 series, Switzerland). The extraction was done in triplicate for each solvent and 
the resulting extracts were stored in a sealed plastic container at $4^{\circ} \mathrm{C}$ until further investigation.

\subsection{Total phenolic Contents (TPC)}

Total phenolic content was estimated by Folin-Ciocalteu method as described in Shan et al. (2005) with slight modification using gallic acid as standard. To $0.5 \mathrm{~mL}$ of the extract $(5 \mathrm{mg} / \mathrm{mL}), 2 \mathrm{~mL}$ Folin-Ciocalteu reagent (diluted ten times) was added and the mixture was left for $5 \mathrm{~min}$ and then $1 \mathrm{~mL}(75 \% \mathrm{w} / \mathrm{w})$ of sodium carbonate was added. The absorbance of the resulting blue color was measured at $765 \mathrm{~nm}$ with a UV- visible spectrophotometer (JENWAY, 96500, UK) after incubation for $90 \mathrm{~min}$ at room temperature. The total phenolic content was estimated from gallic acid $(1-100 \mu \mathrm{g} / \mathrm{mL})$ calibration curve $\left(\mathrm{y}=0.02 \mathrm{x}+0.09, \mathrm{R}^{2}=0.99\right)$ and results were expressed as milligram gallic acid equivalent/gram of dry extract (mgGAE/g).

\subsection{Determination of Antioxidant Activity}

\subsubsection{DPPH method}

The capacity of kocho samples to scavenge free radical was measured with the stable radical of DPPH using method as described by Iqbal et al. (2005), , with minor modification. Two $\mathrm{mL}$ of freshly prepared DPPH solution $(0.06 \%, \mathrm{w} / \mathrm{v})$ in methanol was mixed with different concentrations $((0.1 \mathrm{up}$ to $5 \mathrm{mg} / \mathrm{mL})$ of $1 \mathrm{~mL}$ of extract and reference standards (BHT) dissolved in methanol. The mixtures were vortexed and kept in a dark room for $30 \mathrm{~min}$ at room temperature. The absorbance of the resulting solution was then taken at $520 \mathrm{~nm}$. Methanol was used as blank. The ability to scavenge the DPPH radical was calculated using the following equation:

$$
\text { DPPH scavenged }(\%)=\frac{(A c-A s)}{A c} \times 100
$$

Where $A \mathrm{c}$ is the absorbance of the control and $A \mathrm{~s}$ is the absorbance in presence of the sample of the extracts The antioxidant activity of the extract was expressed as $\mathrm{IC}_{50}$. $\mathrm{The}_{\mathrm{IC}} \mathrm{I}_{50}$ value was defined as the concentration of extracts that scavenges the DPPH radical by $50 \%$. The value (in $\mathrm{mg} / \mathrm{mL}$ ) was extrapolated by plotting percentage inhibition of sample against the corresponding sample concentration.

\subsubsection{Determination total antioxidant activity by phosphomolybdenum method}

The total antioxidant activity of the crude extracts was evaluated by the phosphomolybdenum method (Prieto $e t$ al., 1999) with slight modification. The method is based on the reduction of Mo (VI) to Mo (V) by the antioxidant compounds or crude extract and subsequent formation of green Mo (V) complexes with a maximal absorption at $695 \mathrm{~nm}$ at acidic medium (Mohamed et al., 2011). Plant extract $(0.3 \mathrm{~mL})$ was mixed with $3 \mathrm{~mL}$ of reagent solution $(0.6 \mathrm{M}$ sulphuric acid, $28 \mathrm{mM}$ sodium phosphate and $4 \mathrm{mM}$ ammonium molybdate). The samples were incubated at $95{ }^{\circ} \mathrm{C}$ for $90 \mathrm{~min}$, cooled to room temperature and absorbance was measured at 695 $\mathrm{nm}$ and methanol $(3 \mathrm{~mL})$ was used as blank. The total antioxidant activity was expressed as milligram butylated hydroxyltoluene equivalent/gram of dried extract $(\mathrm{mgAAE} / \mathrm{g})$ based on the calibration curve; $\mathrm{y}=0.301 \mathrm{x}+0.002$, $\mathrm{R}^{2}=0.99$.

\subsection{Statistical Analysis}

The data were subjected to analysis of variance (ANOVA) and Duncan's multiple range tests were used for mean separation at $\mathrm{p}<0.05$. Linear regression analysis was used to calculate $\mathrm{IC}_{50}$ value. Pearson correlations between antioxidant activities, total phenolic contents were considered at $\mathrm{p}<0.05$.

\section{Result and Discussions}

\subsection{Total Phenolic Content of Kocho}

The total phenolic content of Kocho was expressed as milligram of gallic acid equivalent per gram of dried extract (mgGAE/g) as shown in Figure 1. In all samples methanol extracts had higher total phenolic content than that of aqueous extracts. Phenolic content of methanol Kocho extracts analyzed in the study ranged from $1.32 \pm$ $0.02 \mathrm{mgGAE} / 100 \mathrm{~g}$ for unfermented sample to $9.27 \pm 0.9 \mathrm{mgGAE} / 100 \mathrm{~g}$ for Kocho fermented for 45 day. Among the aqueous extracts, Kocho fermented for 60 days had the highest $(p<0.05)$ phenolic content, while unfermented Kocho sample had the lowest phenolic content. Similarly the total phenolic content of methanol extracts of fermented Kocho increased with increasing the period of fermentation. The total phenolic content of Kocho fermented for 45 days was the highest $(\mathrm{p}<0.05)$. Whereas, the unfermented sample had the lowest total phenolic content $(\mathrm{p}<0.5)$. The result increased up to 45 days. After 60 days of fermentation the total phenolic content decreased gradually but no significance level $(p>0.05)$ was observed. But the total phenolic content all fermented samples was significantly higher than that of unfermented sample. These results were consistent with findings on fermented Okra seeds (Adetuyi and Ibrahim 2014), Cabbage (Sun et al., 2009), and Jaruk tigarun (Nazarni et al., 2016), traditional fermented food from South Borneo Indonesia, where fermentation caused increase in the total phenolic contents. In natural form, phenolic compounds are combined or bound with sugar 
which reduces their availability to organism. Many studies indicated that deglycosilation of phenolic compounds could be performed through microbial fermentation due to glycosyl hydrolase family activities (Huynh et al., 2014). These enzymes are well known for their deglycosylation capability by hydrolyzing the different glycosidic bonds existing between sugars and phenolic compounds, causing a significant increase in the amount of different free phenolic compounds (Cho et al., 2009; Lee et al., 2013; Di Gioia et al., 2014 ).

Table 1: Total phenolic content (mgGAE/g of dried extract) of methanol and water extracts of Kocho.

\begin{tabular}{lll}
\hline Fermentation period & Water extract & Methanol extract \\
\hline Fresh & $0.32 \pm 0.08^{\mathrm{a}}$ & $1.32 \pm 0.02^{\mathrm{a}}$ \\
15 days & $2.75 \pm 0.05^{\mathrm{b}}$ & $5.57 \pm 0.14^{\mathrm{bc}}$ \\
30 days & $4.86 \pm 0.10^{\mathrm{bc}}$ & $5.88 \pm 0.20^{\mathrm{bc}}$ \\
45 days & $4.98 \pm 0.07^{\mathrm{bc}}$ & $9.27 \pm 0.44^{\mathrm{d}}$ \\
60 days & $5.34 \pm 0.88^{\mathrm{c}}$ & $8.00 \pm 0.56^{\mathrm{c}}$ \\
75 days & $5.03 \pm 0.11^{\mathrm{c}}$ & $5.93 \pm 0.12^{\mathrm{bc}}$ \\
90 days & $4.98 \pm 0.06^{\mathrm{bc}}$ & $5.82 \pm 0.22^{\mathrm{bc}}$ \\
105 days & $4.78 \pm 0.13^{\mathrm{bc}}$ & $5.60 \pm 0.58^{\mathrm{bc}}$ \\
120 days & $4.41 \pm 0.03^{\mathrm{bc}}$ & $5.53 \pm 0.70^{\mathrm{bc}}$
\end{tabular}

Values are expressed as mean $\pm \mathrm{SD}(\mathrm{n}=3)$ from triplicate experiments .Values within a column with different letters are significantly different at $\mathrm{p}<0.05$.

\subsection{DPPH Free Rradical Scavenging Activity}

Scavenging the stable DPPH radical model is a widely used method to evaluate in vitro antioxidant activity. DPPH is a stable free radical with characteristic absorption at $520 \mathrm{~nm}$ and antioxidants react with DPPH radical and convert it to diamagnetic 2, 2-diphenyl-1-picrylhydrazine molecule. The degree of discoloration indicates the scavenging potential of the antioxidant extract, which is due to the hydrogen donating ability (Von Gadow et al., 1997). Figures 2 and 3 show dose dependence curve for DPPH radical scavenging activity of methanol and water extracts of fermented Kocho which quantified by its absorbance reduction at a wavelength of $520 \mathrm{~nm}$. As concentration of sample increased, the percent of DPPH scavenging increased. Generally, in response to fermentation treatment, there was an increase in relative percentage of radical scavenging activity in all fermentation periods, compared to the control. The result obtained was in accordance with previous research done on red cabbages by Hunaefi et al. (2013), who reported an increase in the percentage of radical scavenging activity in fermented cabbage compared with unfermented cabbage as a control. The increase may be due to the increase in acidic value during fermentation that is liberating bound flavonoid components and making it more bio available (Ashish et al., 2014). Fermentation time did significantly increase the DPPH radical-scavenging activities for all extracts, as compared to unfermented pulverized corm. Contrary to the present result, fermented Kocho sample collected from South Western Ethiopia, showed weaker antioxidant activity than the unfermented pulverized corm of Enset (Forsido et al., 2013).

Table 2 shows $\mathrm{IC}_{50}$ value, which is the inhibition concentration of sample extract required to decrease initial DPPH activity by $50 \%$. DPPH scavenging activities were also reflected in the $\mathrm{IC}_{50}$ values where the value for methanol extract of Kocho fermented for 60 days $\left(\mathrm{IC}_{50}=0.15 \pm 0.02 \mathrm{mg} / \mathrm{mL}\right)$ was significantly $(\mathrm{p}<0.05)$ lower (stronger antioxidant activity) than that of all fermented Kocho samples. The unfermented fresh sample showed the weakest ( $\mathrm{IC}_{50}>5 \mathrm{mg} / \mathrm{mL}$ ) DPPH scavenging activity. Similarly, the water extract of Kocho fermented for 60 days showed the strongest $\mathrm{DPPH}$ scavenging $\left(\mathrm{IC}_{50}=0.81 \pm 0.47 \mathrm{mg} / \mathrm{mL}\right)$ activity. Further increasing the fermentation period (above 60 fermentation days) decreased the DPPH scavenging potential of Kocho extract. BHT as a reference showed stronger DPPH scavenging activity $(\mathrm{p}<0.05)$ than that of all fermented Kocho extracts. Different studies reported (Moktan et al., 2008; Ademiluyi and Oboh, 2011) that prolonged fermentation decreased the available phenolic compounds because of the microorganisms grow using these compounds as substrates (Ehsan et al., 2010). Therefore the optimal fermentation period is important to get the maximum amount of phenolic compounds during fermentation of food products. 


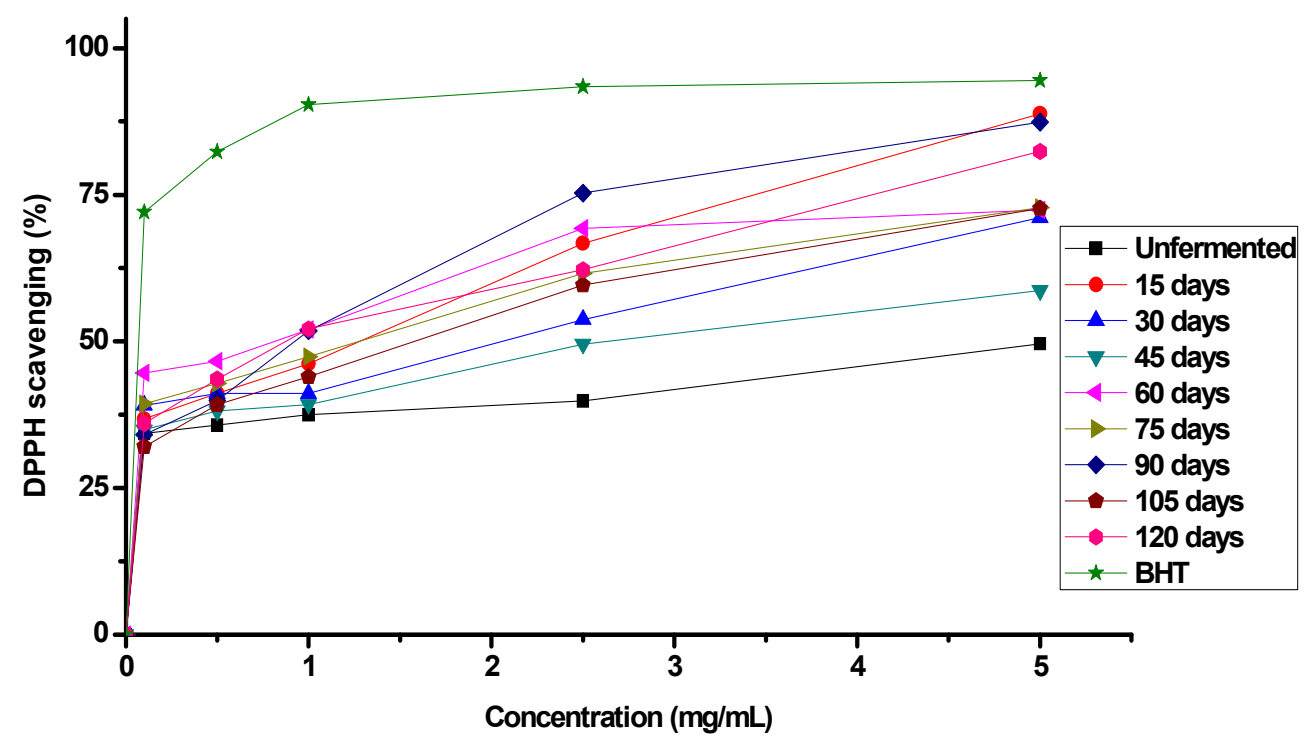

Figure 2: DPPH radical scavenging activity aqueous extracts of Kocho, fermented for different period of time and control (BHT).Values are average of triplicate measurements (mean $\pm \mathrm{SD}$ ).

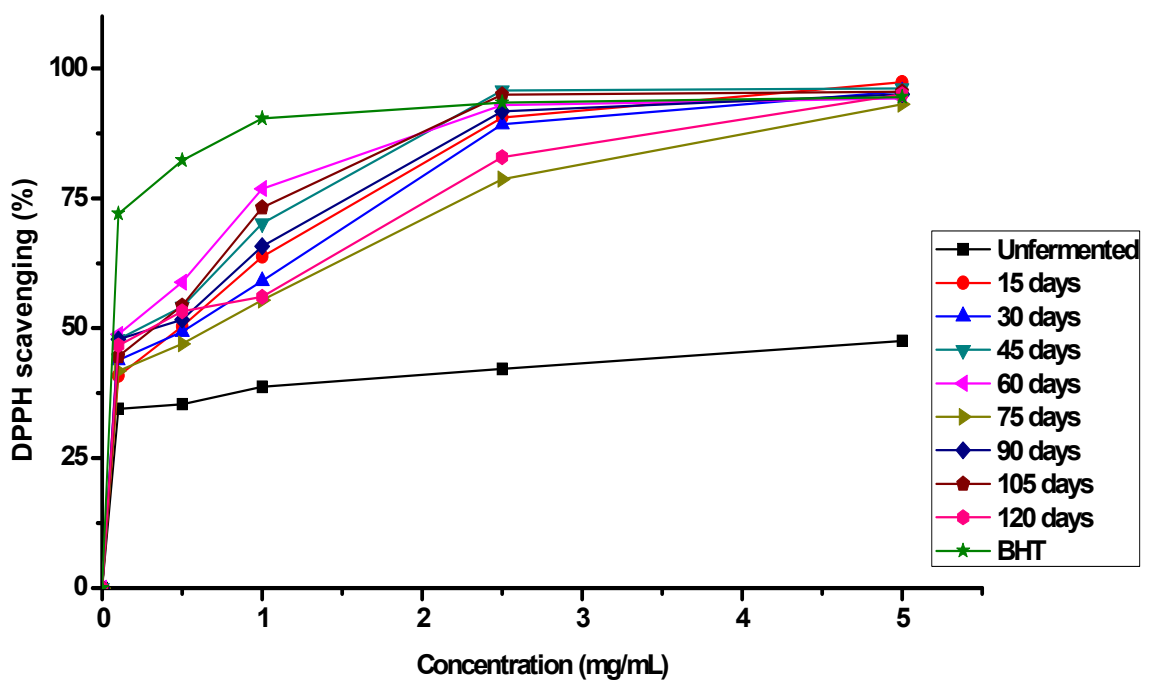

Figure 3: DPPH radical scavenging activity methanol extracts of Kocho, fermented for different period of time and control (BHT).Values are average of triplicate measurements (mean $\pm \mathrm{SD}$ ). 
Table 2: $\mathrm{IC}_{50}(\mathrm{mg} / \mathrm{mL})$ of DPPH scavenging activity of methanol and water extracts Kocho fermented for different period of time.

\begin{tabular}{lll}
\hline Fermentation period (days) & Aqueous extract & Methanol extract \\
\hline Unfermented & $>5$ & $>5$ \\
15 & $1.29 \pm 0.09^{\mathrm{bc}}$ & $0.47 \pm 0.02^{\mathrm{abc}}$ \\
30 & $2.10 \pm 0.39^{\mathrm{d}}$ & $0.52 \pm 0.04^{\mathrm{bc}}$ \\
45 & $2.66 \pm 0.42^{\mathrm{e}}$ & $0.25 \pm 0.19^{\mathrm{ab}}$ \\
60 & $0.81 \pm 0.47^{\mathrm{b}}$ & $0.15 \pm 0.02^{\mathrm{a}}$ \\
75 & $1.16 \pm 0.03^{\mathrm{bc}}$ & $0.67 \pm 0.23^{\mathrm{c}}$ \\
90 & $0.94 \pm 0.10^{\mathrm{bc}}$ & $0.39 \pm 0.23^{\mathrm{abc}}$ \\
105 & $1.55 \pm 0.18^{\mathrm{c}}$ & $0.33 \pm 0.04^{\mathrm{abc}}$ \\
120 & $1.03 \pm 0.39^{\mathrm{c}}$ & $0.27 \pm 0.08^{\mathrm{ab}}$ \\
\hline
\end{tabular}

Values are expressed as mean \pm SD $(n=3)$ from triplicate experiments.. Values within a column with different letters are significantly different at $\mathrm{p}<0.05$.

\subsection{Total antioxidant activity using phosphomolybdenum assay}

Similar to DPPH scavenging, the methanol extract showed stronger total antioxidant activity than that of aqueous extracts (Table 3). Among the methanol extracts, Kocho fermented for 60 days showed the strongest total antioxidant activity with the value of $0.43 \pm 0.04 \mathrm{mgAAE} / \mathrm{g}$. whereas unfermented sample showed the significantly the weakest $(p<0.05)$ total antioxidant. No significant difference $(p>0.05)$ was found between the total antioxidant activities of Kocho fermented 15 up to 30 days and also these values have no significant difference with Kocho fermented 75 up to 90 days. But these values showed significantly $(\mathrm{p}<0.05)$ stronger total antioxidant activity than Kocho fermented between 105 and 120 days. The total antioxidant activities of all fermented Kocho samples were significantly stronger $(p<0.05)$ than that of unfermented sample. Similarly, the water extract of Kocho fermented for 60 days showed the strongest total antioxidant activity $(\mathrm{p}<0.05)$.

Table 3: Total antioxidant activity (mgAAE/g of dried extract) of methanol and water extracts of Kocho fermented for different period of time.

\begin{tabular}{ccc}
\hline Fermentation period & Aqueous extract & Methanol extract \\
\hline Unfermented & $0.03 \pm 0.01^{\mathrm{a}}$ & $0.17 \pm 0.01^{\mathrm{a}}$ \\
15 days & $0.13 \pm 0.01^{\mathrm{b}}$ & $0.28 \pm 0.09^{\mathrm{bc}}$ \\
30 days & $0.18 \pm 0.02^{\mathrm{bc}}$ & $0.33 \pm 0.04^{\mathrm{cd}}$ \\
45 days & $0.18 \pm 0.07^{\mathrm{bc}}$ & $0.38 \pm 0.04^{\mathrm{de}}$ \\
60 days & $0.28 \pm 0.06^{\mathrm{d}}$ & $0.43 \pm 0.04^{\mathrm{e}}$ \\
75 days & $0.23 \pm 0.08^{\mathrm{cd}}$ & $0.38 \pm 0.02^{\mathrm{de}}$ \\
90 days & $0.20 \pm 0.04^{\mathrm{bcd}}$ & $0.37 \pm 0.03^{\mathrm{de}}$ \\
105 days & $0.17 \pm 0.03^{\mathrm{bc}}$ & $0.23 \pm 0.07^{\mathrm{ab}}$ \\
120 days & $0.17 \pm 0.04^{\mathrm{bc}}$ & $0.23 \pm 0.08^{\mathrm{ab}}$
\end{tabular}

Values are expressed as mean \pm SD $(n=3)$ from triplicate experiments. Values within a column with different letters are significantly different at $\mathrm{p}<0.05$.

\subsection{Correlation analysis}

It is well known that the antioxidant activity of a plant extracts are largely depending on both the concentration and the nature of phenolic compounds present in the extract (Catherine et al., 1996; Weng and Huang. 2014). In this study, the relationship between total phenolic content and antioxidant activity Kocho fermented for different period of time extracted by methanol and water solvents was evaluated (Table 4). The results showed good linear correlation in the cases of DPPH scavenging activity $\left(\mathrm{R}^{2}=0.53, \mathrm{p}>0.05\right)$ and total antioxidant activity $\left(\mathrm{R}^{2}=\right.$ $0.52, \mathrm{p}>0.05)$ with total phenolic content of methanol extracts of Kocho fermented up to 120 days. In case of aqueous extracts the total phenolic was weakly correlated $\left(\left(\mathrm{R}^{2}=0.48, \mathrm{p}>0.05\right)\right.$ with total antioxidant activity but moderately correlated $\left(\mathrm{R}^{2}=0.63, \mathrm{p}>0.05\right)$ with DPPH scavenging activity of all Kocho samples. 
Table 4: Correlation of antioxidant activities with TPC of Kocho samples during fermentation processes.

\begin{tabular}{ccc}
\hline Extract & Correlation factor & Correlation coefficient $\left(\mathrm{R}^{2}\right)$ \\
\hline \multirow{3}{*}{ Water } & TPC & +0.53 \\
\cline { 2 - 3 } & Vs. DPPH Scavenging $(\%)$ & +0.52 \\
\hline \multirow{2}{*}{ Methanol } & TPC & +0.63 \\
& Vs. mg BHTE/100g & +0.48 \\
\cline { 2 - 3 } & TPC & \\
\hline
\end{tabular}

\section{Conclusions}

This study demonstrated that fermentation caused a marked increase in total phenolic content which then enhanced DPPH radical-scavenging ability and total antioxidant activity of the Kocho extracts. Fermentation time affected the antioxidant activities of Kocho and fermentation for 60 days seemed to be applicable as exemplified by the least $\mathrm{IC}_{50}$ value of $\mathrm{DPPH}$ radical-scavenging ability and highest value of total antioxidant power. The methanol extract showed the strongest DPPH scavenging and total antioxidant activity. Whereas, in all extraction periods aqueous extracts exhibited weaker DPPH scavenging and total antioxidant activities.

In conclusion, extending of fermentation time had resulted differences in total phenolic contents and antioxidant activity of Kocho. Therefore, fermentation played a significant role in Kocho preparation by enrichment of the product through development and release of phenolic compounds due to the action of cell wall-degrading enzymes produced through fermentation of bioactive components and enhancing antioxidant capacity. Generally, the selection of appropriate Enset varieties, improved processing methods, and recommended fermentation time are good practice for the processing of tradition food products, such as Kocho an Ethiopian traditional fermented food. This work was carried out with the analysis of crude Kocho extract. However, further studies are needed to evaluate the in vivo experiments of various solvent extracts and individual bioactive compounds in various animal models.

\section{Acknowledgements}

I would like to acknowledge Hawassa College of Education for the financial assistance provided and use of laboratory facilities.

\section{References}

Ademiluyi, A.O. and Oboh, G. 2011. Antioxidant properties of condiment produced from fermented bambara groundnut (Vigna subterranean L. Verdc). Journal of Food Biochemistry, 35:1145 -1160.

Adetuyi, F. O. and Ibrahim T. A. 2014. Effect of fermentation time on the phenolic, flavonoid and vitamin C contents and antioxidant activities of Okra (Abelmoschus esculentus) seeds. Nigerian Food Journal 32 (2): $128-137$.

Ajebu, N., Adugna, T., Lars O. E. and Frik, S. 2008. Yield and mineral content of ten enset (Ensete ventricosum) varieties. Tropical Animal Health and Production, 40 (4): 299-309.

Ashish, A. P., Mrudula, C. M. and Rajesh, J. 2014. Effect of yeast fermentation on nutraceutical and antioxidant properties of rice bran. International Journal of Agricultural and Food Science, 4(1): 59-65.

Balcha, A. 1990. Some notes on traditional medicines in Gurage land. Paper prepared in fulfillment of Host. 530, a postgraduate course in History, Addis Ababa University.

Biruk, A., Ayelign, M., Tewodros, T. \& Elias, G. 2012. Ensete ventricosum (WELW.) CHEESMAN: A Cheap and Alternative Gelling Agent foe Pineaple (Ananas comosus VAR. Smooth Cayenne) In Vitro Propagation. Journal of microbiology, Biotechnology and food Sciences, 2 (2): 640-652.

Brandt, S. A., Spring, A., Hiebsch, C., McCabe, J. T., Tabogie, E. Diro, M., Wolde-Michael, G., Yntiso, G. Shigeta M. and Tesfaye, S. 1997. The "Tree Against Hunger". Enset-Based Agricultural Systems in Ethiopia. American Association for the Advancement of Science with Awassa Agricultural Research Center, Kyoto University Center for African Area Studies and University of Florida, Washington, DC, USA, 66 pp.

Catherine, A., Rice-evans, N., Miller, J. and George, P. 1996. Structure-antioxidant activity relationships of flavonoids and phenolic acids Free Radical Biology and Medicine, 20 (7): 933-956.

Cho, K.M., Hong, S.Y., Math, R.K., Lee, J.H., Kambiranda, D.M., Kim, J.M., Islam, S.M.A., Yun, M.G., Cho, J.J., Lim, W.J. 2009. Biotransformation of phenolics (isoflavones, flavanols and phenolic acids) during the fermentation of cheonggukjang by Bacillus pumilus HY1. Food Chemistry, 114:413-419.

Di Gioia, D., Strahsburger, E., Lopez de Lacey, A. M., Bregola, V., Marotti, I., Aloisio, I., Biavati, B., Dinelli, G. 2014. Flavonoid bioconversion in Bifidobacterium pseudocatenulatum B7003: A potential probiotic strain for functional food development. Journal of Functional Food, 7:671-679. 
Ehsan, K., Ehsan, O., Rudi, H. and Jaafar, H.Z.E. 2010. Solid state fermentation effects on Pistachio Hulls antioxidant activities presented in the 3rd International Conference for Value Added Agricultural Products (3rd Fer VAAP Conference). KKU Research Journal 15 (5): 260 -266.

Forsido S. F., Rupasinghe, H. P. and Astatke T. 2013. Antioxidant capacity total phenolics and nutritional content of selected Ethioipain stable food ingredients. International journal of Food Science and Nutrition, 64 (8): $915-920$

Gebre-mariam, T. and Schmidt, P. C. 1996. Isolation and Physicochemical Properties of Enset starch. Starchstake, 48(6):208-214.

Holscher, D. and Schneider, B. 1998. Phentl phenalenones from Ensete ventricusum, Phytochemistry, 49: 21552177.

Hunaefi, D., Akumo, D. N. and Smetanska, I. 2013. Effect of Fermentation on Antioxidant Properties of Red Cabbages. Food Biotechnology, 27:1, 66-85

Huynh, N. T., John, V. C., Smagghe, G. and Katleen, R. 2014. Improved Release and Metabolism of Flavonoids by Steered Fermentation Processes: A Review International Journal of Molecular Science, 15(11): 1936919388.

Iqbal, S., Bhanger, M.I. and Anwar, F. 2005. Antioxidant properties and components of some commercially available varieties of rice bran in Pakistan. Journal of Food Chemistry, 93: 265-272.

Lee, S.-H., Seo, M.-H. and Oh, D.-K. 2013. Deglycosylation of isoflavones in isoflavone-rich soy germ flour by Aspergillus oryzae KACC 40247. Journal of Agricultural Food Chemistry, 61:12101-12110.

Melesse, M., Sileshi, N. and Tamirat, B. 2015. An ethnobotanical study of medicinal plants of the Kembatta ethnic group in Enset-based agricultural landscape of Kembatta Tembaro (KT) Zone, Southern Ethiopia. Asian Journal of Plant Science and Research, 2015, 5(7):42-61.

Moktan, B., Saha, J. and Sarkar, P.K. 2008. Antioxidant activities of soybean as affected by Bacillus fermentation to kinema. Food Research International, 41: 586-593.

Nazarni, R., Purnama, D., Umar, S. and Eni, H. 2016. The effect of fermentation on total phenolic, flavonoid and tannin content and its relation to antibacterial activity in jaruk tigarun (Crataeva nurvala, Buch HAM). International Food Research Journal, 23(1): 309-315.

Negash, A., Anke, A. 2004. The significance of enset culture and biodiversity for rular household food and livelihood security in South west Ethiopia. Agriculture \& Human Values, 21: 61-71.

Prieto, P., Pineda, M. and Aguilar, M.1999. Spectrophotometric quantitation of antioxidant capacity through the formation of a phosphomolybdenum complex: specific application to the determination of Vitamin E, Analytical Biochemistry, 269:337-341

Samuel, M. A. 2014. Livestock Feeds and Feeding System in Enset (Ensete ventricosum) Dominatd mixed Farming system of Southern Ethiopia. Online Journal of Animal and Feed Research, 4(6): 150-158.

Shan, B., Cai Y. and Sun M. Corke H 2005. Antioxidant capacity of 26 spice extracts and characterization of their phenolic constituents, Journal of Agricultural and Food Chemistry, 53: 7749-7759.

Tiruha, H. K., Kebede, A. A. and Edessa, N. G. 2014. The microbiology of Kocho: An Ethiopian Traditionally Fermented Food from Enset ( ) Ensete ventricosum. International journal of life sciences, 8(1):7-13.

Von Gadow, A., Joubert, E. \& Hansmann, C. 1997. Comparison of the antioxidant aactivity of aspalathin with that of other plant phenols of Rooibos tea (Aspalathus linearis). $\alpha$-Tocopherol, BHT, and BHA, Journal of Agricultural and Food Chemistry, 45: 632-638.

Weng, X. C. and Huang, Y. 2014. Relationship structure-antioxidant activity of hindered phenolic compounds. GRASAS Y ACEITES, 65(4):1-8.

Yemataw, Z., Bekele, A., Blomme, G., Muzemil, S., Tesfaye, K. and Jacobsen K. 2018. A review of enset (Ensete ventricosum (Welw.) Cheesman) diversity and its use in Ethiopia. Fruits, 73(6): 301-309.

Zebene, K., Isabel, M., Ana, L., Joana, F., Sisay, F., Abubeker, Y., Helena, P. and Hanna, B. 2018. Characterization of crop residues from false banana/Ensete ventricosum/ in Ethiopia in view of a fullresource valorization. PLOS ONE, 13(7):1-21

Zerihun, Y., Kassahun, T., Awole, Z. and Guy, B. 2016. Exploiting indigenous knowledge of subsistence farmers' for the management and conservation of Enset (Ensete ventricosum (Welw.) Cheesman) (musaceae family) diversity on-farm. Journal of Ethnobiology and Ethnomedicine, 12(:34: 2-25. 